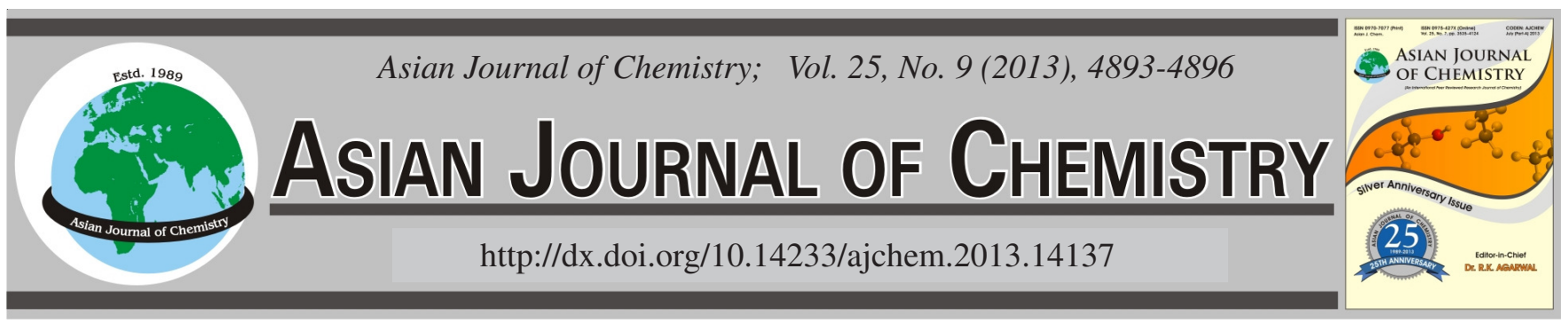

\title{
A Novel Inorganic-Organic Hybrid Material Based on Monosubstituted Keggin-Type Polyoxometalates by a Metal-Nitrogen of Covalent Bonding
}

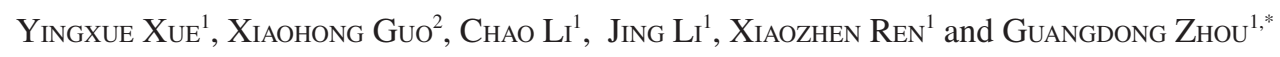

${ }^{1}$ College of Chemistry, Jilin University, Changchun 130023, P.R. China

${ }^{2}$ Changchun No. 2 High School, Changchun 130061, P.R. China

*Corresponding author: E-mail: zhougd@jlu.edu.cn; xxyyxx0129@126.com

(Received: 29 May 2012;

Accepted: 8 March 2013)

AJC-13097

\begin{abstract}
A new inorganic-organic hybrid material $\mathrm{Na}(\mathrm{ANIH})_{4} \mathrm{ANI}\left[\mathrm{PW}{ }_{11} \mathrm{Ni}(\mathrm{ANI}) \mathrm{O}_{39}\right] \cdot 12 \mathrm{H}_{2} \mathrm{O}(\mathrm{ANI}=$ aniline $)$ was prepared based on transitionmetal monosubstituted keggin type polyoxometalates $\left[\mathrm{PW}_{11} \mathrm{Ni}_{(}\left(\mathrm{H}_{2} \mathrm{O}\right) \mathrm{O}_{39}\right]^{5-}$ as inorganic species and aniline as organic ligand by a covalent bonding of Ni-N. The as-prepared hybrid material was characterized by elemental analysis, IR spectroscopy, TG-DTA analyses, UVvisible spectra and X-ray photoelectron spectroscopy (XPS). Elemental analysis and TG-DTA results confirm the formula of the hybrid material. Experimental results of UV-VIS, IR and XPS approve that the Ni-N covalent bond is formed between the transition-metal in the Keggin-type anion $\left[\mathrm{PW}_{11} \mathrm{Ni}\left(\mathrm{H}_{2} \mathrm{O}\right) \mathrm{O}_{39}\right]^{5-}$ and the nitrogen atom of ANI and the $\mathrm{ANIH}^{+}$exists as counter ion. Moreover, photocatalytic activity of the as-prepared hybrid material was investigated by photodegradation of dye rhodamine B under UV irradiation and the results showed that the hybrid material exhibited high photocatalytic activity for treatment of dye-containing wastewater.
\end{abstract}

Key Words: Hybrid material, Keggin type, Polyoxometalates, Photocatalytic activity.

\section{INTRODUCTION}

Polyoxometalates (POMs) are a well-known class of structurally well-defined anionic metal oxide clusters that remain a considerable focus, since their fascinating redox character, unique molecular structure and electronic versatility give rise to potential applications in catalysis, photochemistry, electrochromism, magnetism, medicine and biology ${ }^{1,2}$. Recent study has shown that POMs can be viewed as ideal inorganic species to be incorporated into organic complexes for the formation of various POM-based hybrid materials ${ }^{3}$. In addition to their large diversity in chemical and physical properties and shape, hybrid materials also possess the functionalities of POMs and the merits of organic molecules via incorporating POMs into organic molecules, thus can be applied in many fields. Preparation of polyoxometalate-based hybrids can mainly be classed into two main approaches: (a) electrostatic interactions between the anionic polyoxometalates and cationic species that can be organic, for example, ammonium salts or metal organics ${ }^{4}$; (b) formation of covalent bonds. This method requires covalent attachment of the organic donor on the polyoxometalate surface and the hybrid materials of this type have better stability and high strength ${ }^{5}$. One of the most notable methods is the reaction of amine with polyoxometalate through the substitution of terminal oxo moieties by organoimine ${ }^{6,7}$. The field of organoimido derivatives of POMs has gained more and more interest after the outstanding reports of Maatta ${ }^{8}$, Errington ${ }^{9}$ and Proust $^{10}$, in as much as these compounds, the organic $\pi$-electrons may extend their conjugation to the inorganic framework, remarkably modifying the electronic structure and redox properties of the parent POM clusters ${ }^{11}$. But examples of covalent bond formed between substituted transition-metal in the Keggintype polyoxometalates and organic ligand are rarely observed.

In this paper, we firstly report a novel inorganic-organic hybrid material $\mathrm{Na}(\mathrm{ANIH})_{4} \mathrm{ANI}\left[\mathrm{PW}_{11} \mathrm{Ni}(\mathrm{ANI}) \mathrm{O}_{39}\right] \cdot 12 \mathrm{H}_{2} \mathrm{O}$. Aniline (ANI) was selected as organic ligand to interact with transition-metal in the Keggin type anion $\left[\mathrm{PW}_{11} \mathrm{Ni}\left(\mathrm{H}_{2} \mathrm{O}\right) \mathrm{O}_{39}\right]^{5-}$. Our strategy involves incorporating monosubstituted POMs into organic ligand by forming $\mathrm{Ni}-\mathrm{N}$ covalent bond between the transition-metal in the $\left[\mathrm{PW}_{11} \mathrm{Ni}\left(\mathrm{H}_{2} \mathrm{O}\right) \mathrm{O}_{39}\right]^{5-}$ and the nitrogen atom of ANI. In addition, the photocatalytic activity of the hybrid material was investigated via photodegradation of rhodamine B under UV light radiation.

\section{EXPERIMENTAL}

All chemicals and solvents in this study are reagent grade and used as received from commercial sources without further purification. $\mathrm{K}_{5}\left[\mathrm{PW}_{11} \mathrm{Ni}\left(\mathrm{H}_{2} \mathrm{O}\right) \mathrm{O}_{39}\right]$ was prepared by the literature method $^{12}$. The contents of $\mathrm{Ni}, \mathrm{W}, \mathrm{Na}$ and $\mathrm{P}$ were determined by a Perkin-Elmer Optima 3300DV inductively coupled plasma (ICP) spectrometer. Elemental analyses (C, H and N) were performed on a Perkin-Elmer $2400 \mathrm{CHN}$ elemental analyzer. 
Infrared spectra in the range of $4000-400 \mathrm{~cm}^{-1}$ ( $\mathrm{KBr}$ disks) were measured with a Nicolet-Impact 400 Fourier-transformed infrared (FTIR) spectrometer. Thermogravimetric analysis (TG) and differential thermal analysis (DTA) were conducted on a Netzscn STA 449C thermogravimetric analyzer. Samples were heated under an air atmosphere at 303.2 to $973.2 \mathrm{~K}$ and at a heating rate of $10 \mathrm{~K} / \mathrm{min}$. XPS spectra were taken on an VG ESCA LAB MKII photoelectronic spectrometer with $\mathrm{MgK}_{\alpha}$ as excitation source and the combination energy criterion was $\mathrm{C} 1 \mathrm{~s}=284.6 \mathrm{eV}$. UV-visible spectral measurements were recorded on a Shimadzu UV-1700PC spectrometer.

Preparation of $\mathrm{Na}(\mathrm{ANIH})_{4} \mathrm{ANI}\left[\mathrm{PW}_{11} \mathbf{N i}(\mathrm{ANI}) \mathrm{O}_{\mathbf{3 9}}\right] \cdot \mathbf{1 2}_{\mathbf{2}} \mathrm{O}$ : $\mathrm{Na}_{2} \mathrm{WO}_{4} \cdot 2 \mathrm{H}_{2} \mathrm{O}(6.6 \mathrm{~g}, 20 \mathrm{mmol})$ and $\mathrm{Na}_{2} \mathrm{HPO}_{4}(0.26 \mathrm{~g}, 1.8$ mmol) were dissolved in $40 \mathrm{~mL} \mathrm{H}_{2} \mathrm{O}$. This solution was heated to $80-90{ }^{\circ} \mathrm{C}$ and acidified with conc. $\mathrm{HNO}_{3}$ until $\mathrm{pH} 4.8$. Aqueous $\mathrm{Ni}\left(\mathrm{NO}_{3}\right)_{2} \cdot 9 \mathrm{H}_{2} \mathrm{O}(0.44 \mathrm{~g}, 2.4 \mathrm{mmol}, 3 \mathrm{~mL})$ was added and the $\mathrm{pH}$ was then adjusted to 4.5 by adding small aliquots of $\mathrm{NaHCO}_{3}$. After $0.5 \mathrm{~h}$ of stirring, the solution was cooled to $70^{\circ} \mathrm{C}$ and then aniline $(1.7 \mathrm{~mL})$ was added slowly. After stirring for $4 \mathrm{~h}$, yellow block solids were obtained. Then the solids were filtered out and washed with acetonitrile and water, followed by air-drying at room temperature.

The yield was $23 \%$. Elemental anal. (\%) calcd. (found) for $\mathrm{C}_{36} \mathrm{H}_{70} \mathrm{~N}_{6} \mathrm{O}_{51} \mathrm{PW}_{11} \mathrm{NiNa}$ : C, 12.22 (11.7); H, 1.98 (1.93); N, 2.38 (2.32); P, 0.88 (0.83); W, 57.17 (55.41); Na, 0.65 (0.62); $\mathrm{Ni}, 1.66$ (1.55).

Photocatalytic activity: The photocatalytic activity of the as-prepared hybrid material was investigated via photodegradation of rhodamine $\mathrm{B}$ under UV light radiation. In a photodegradation experiment $150 \mathrm{~mL}$ of fresh aqueous dye solution $(10 \mathrm{mg} / \mathrm{L})$ and photocatalyst (containing $40 \mathrm{mg}$ of pure $\mathrm{K}_{5}\left[\mathrm{PW}_{11} \mathrm{Ni}\left(\mathrm{H}_{2} \mathrm{O}\right) \mathrm{O}_{39}\right], \mathrm{Na}(\mathrm{ANIH})_{4} \mathrm{ANI}\left[\mathrm{PW}_{11} \mathrm{Ni}(\mathrm{ANI}) \mathrm{O}_{39}\right]$ $\left.\cdot 12 \mathrm{H}_{2} \mathrm{O}\right)$ were used. The suspension $(150 \mathrm{~mL})$ was stirred in the dark for $3 \mathrm{~h}$ to obtain a good dispersed reactant and establish adsorption-desorption equilibrium between the dye molecules and the catalyst surface. The solution was irradiated under UV light (125 W high pressure mercury lamp, $312 \mathrm{~nm}$ ) with continuously stirring during the photocatalytic reaction. After the signal intensity of the high pressure mercury lamp became stable, the solution was irradiated. After appropriate time interval of illumination, the $3 \mathrm{~mL}$ of sample was taken out and centrifuged, then the filtrates was analysed by UV spectrophotometer.

\section{RESULTS AND DISCUSSION}

IR spectroscopy: IR spectra of the as-prepared hybrid material have been recorded in the range of $4000-400 \mathrm{~cm}^{-1}$. In Fig. 1b, a weak but obvious peak at $687 \mathrm{~cm}^{-1}$ is attributed to the Ni- $\mathrm{N}^{13}$ covalent bond formed between the transition-metal center in the $\left[\mathrm{PW}_{11} \mathrm{Ni}\left(\mathrm{H}_{2} \mathrm{O}\right) \mathrm{O}_{39}\right]^{5-}$ cluster and the nitrogen atom of aniline. In addition, the spectrum of hybrid material shows bands in the range of $1100-700 \mathrm{~cm}^{-1}$ corresponding to the characteristic $\mathrm{P}-\mathrm{O}$ bond in the central $\mathrm{PO}_{4}$ unit, $\mathrm{W}=\mathrm{O}$ and $\mathrm{W}-\mathrm{O}-\mathrm{W}$ bonds of the clusters, appearing at 1062, 959, 888 and 814 $\mathrm{cm}^{-1}$, respectively, which is similar to the characteristic bands of $\left[\mathrm{PW}_{11} \mathrm{Ni}\left(\mathrm{H}_{2} \mathrm{O}\right) \mathrm{O}_{39}\right]^{5-}$ anion ${ }^{14}$ (Fig. 1a). This result shows that the monosubstituted Keggin unit remains intact in the asprepared hybrid material. Some shifts of the peak positions can be attributed to the interaction of the POMs clusters with organic ligand. A broad band at $3453 \mathrm{~cm}^{-1}$ is assigned to the $\mathrm{O}-\mathrm{H}$ stretch band from water molecule and N-H stretch band from aniline. The $1700-1150 \mathrm{~cm}^{-1}$ region is indicative of the organic ligand in the hybrid material (Fig. 1b). The bending vibrations of $\mathrm{N}-\mathrm{H}$ bonds in aniline are observed at 1601 and $1620 \mathrm{~cm}^{-1}$. The peak at $1491 \mathrm{~cm}^{-1}$ observed for the hybrid material is due to the stretching vibrations of the $\mathrm{C}=\mathrm{C}$ group in aniline ${ }^{15}$. The peaks at 1632 and $1574 \mathrm{~cm}^{-1}$ are assigned to asymmetric bending mode of the $-\mathrm{NH}_{3}{ }^{+}$group in protonated aniline $\mathrm{C}_{6} \mathrm{H}_{5} \mathrm{NH}_{3}{ }^{+}\left(\mathrm{ANIH}^{+}\right)$. In addition, the peaks at 745 and $706 \mathrm{~cm}^{-1}$ in the hybrid material attributed to $\mathrm{W}-\mathrm{O}_{\text {center }}$ bonds in POM clusters overlap the out-of-plane benzene ring deformation band around $690 \mathrm{~cm}^{-1}$ and C-H deformation or bending bands around $750 \mathrm{~cm}^{-1}$ of ANI and $\mathrm{ANIH}^{+16}$. These results reveal the coexistence of aniline and protonated aniline $\mathrm{C}_{6} \mathrm{H}_{5} \mathrm{NH}_{3}{ }^{+}$in the hybrid material. The IR results illuminate that the $\mathrm{Ni}-\mathrm{N}$ covalent bond is successfully formed between $\left[\mathrm{PW}_{11} \mathrm{Ni}\left(\mathrm{H}_{2} \mathrm{O}\right) \mathrm{O}_{39}\right]^{5-}$ and aniline and the protonated aniline $\mathrm{ANIH}^{+}$exists as counter ions.

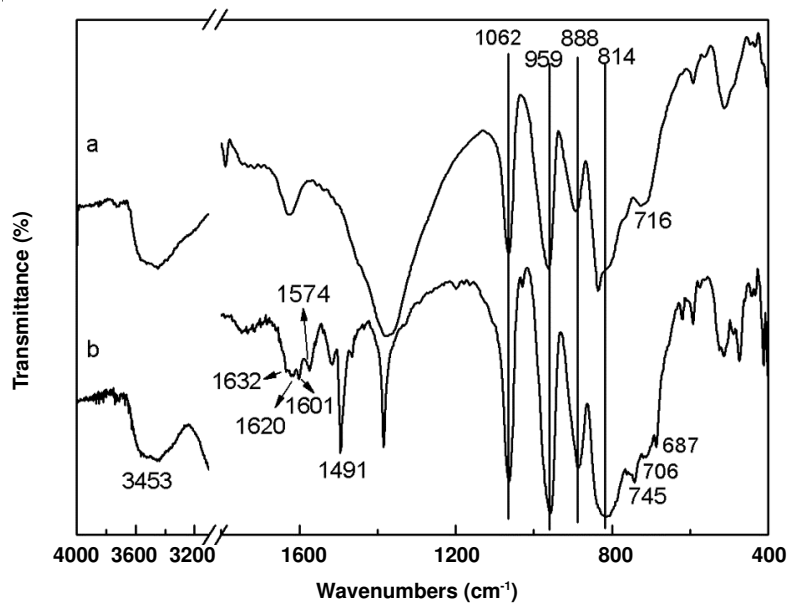

Fig. 1. FT-IR spectra of (a) $\mathrm{K}_{5}\left[\mathrm{PW}_{11} \mathrm{Ni}_{(}\left(\mathrm{H}_{2} \mathrm{O}\right) \mathrm{O}_{39}\right]$ and (b) $\mathrm{Na}(\mathrm{ANIH})_{4} \mathrm{ANI}$ $\left[\mathrm{PW}_{11} \mathrm{Ni}(\mathrm{ANI}) \mathrm{O}_{39}\right] \cdot 12 \mathrm{H}_{2} \mathrm{O}$

UV-visible spectra: UV-visible spectra of the hybrid material are shown in Fig. 2. For the hybrid material, the absorptions at 201 and $253 \mathrm{~nm}$ are assigned to $\mathrm{O} \rightarrow \mathrm{W}$ chargetransfer of $\mathrm{W}=\mathrm{O}$ and $\mathrm{W}-\mathrm{O}-\mathrm{W}$ bonds ${ }^{17}$, respectively, which are consistent with the Keggin-type anion $\left[\mathrm{PW}_{11} \mathrm{Ni}\left(\mathrm{H}_{2} \mathrm{O}\right) \mathrm{O}_{39}\right]^{5-}$ (Fig. 2a), suggesting that the primary Keggin unit in the asprepared hybrid material doesn't change after interacting with organic ligand. In addition, from the insert spectrum of the hybrid material in Fig. 2, a new and broad absorption peak appears at $423 \mathrm{~nm}$ after interaction between $\left[\mathrm{PW}_{11} \mathrm{Ni}_{(}\left(\mathrm{H}_{2} \mathrm{O}\right) \mathrm{O}_{39}\right]^{5-}$ anion and aniline, which is attributed to a charge-transfer transition of aniline molecule to $\mathrm{Ni}^{2+}$, indicating that the as-prepared hybrid material is formed by a covalent bonding of $\mathrm{Ni}-\mathrm{N}$ due to the interaction between transition metal center in the $\left[\mathrm{PW}_{11} \mathrm{Ni}\left(\mathrm{H}_{2} \mathrm{O}\right) \mathrm{O}_{39}\right]^{5-}$ cluster and the nitrogen atom of aniline.

$\mathrm{X}$-Ray photoelectron spectroscopy: Confirmatory evidence for the formation of the polyoxometalate-aniline adduct $\mathrm{Na}(\mathrm{ANIH})_{4} \mathrm{ANI}\left[\mathrm{PW}_{11} \mathrm{Ni}(\mathrm{ANI}) \mathrm{O}_{39}\right] \cdot 12 \mathrm{H}_{2} \mathrm{O}$ is further supported by XPS spectra. The N1s XPS spectrum of the hybrid material is shown in Fig. 3 and the corresponding data of the binding energies are shown in Table-1. For $\mathrm{K}_{5}\left[\mathrm{PW}_{11} \mathrm{Ni}\left(\mathrm{H}_{2} \mathrm{O}\right) \mathrm{O}_{39}\right]$, 


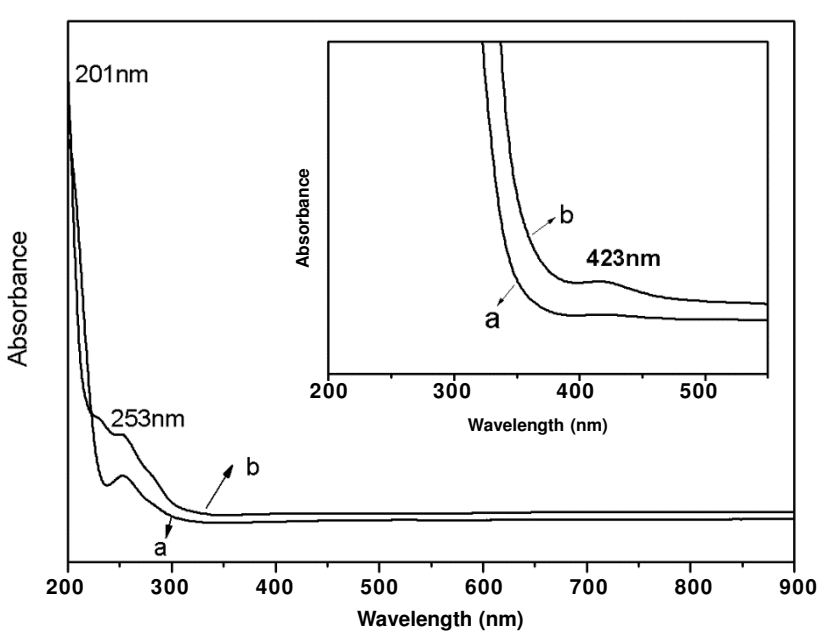

Fig. 2. UV-Visible spectra of (a) $\mathrm{K}_{5}\left[\mathrm{PW}_{11} \mathrm{Ni}\left(\mathrm{H}_{2} \mathrm{O}\right) \mathrm{O}_{39}\right]$ and (b) $\mathrm{Na}(\mathrm{ANIH})_{4} \mathrm{ANI}\left[\mathrm{PW}_{11} \mathrm{Ni}(\mathrm{ANI}) \mathrm{O}_{39}\right] \cdot 12 \mathrm{H}_{2} \mathrm{O}\left(0.3 \times 10^{-6} \mathrm{M}\right)$. Insert: UV-visible spectra of (a) and (b) $\left(1.2 \times 10^{-4} \mathrm{M}\right)$

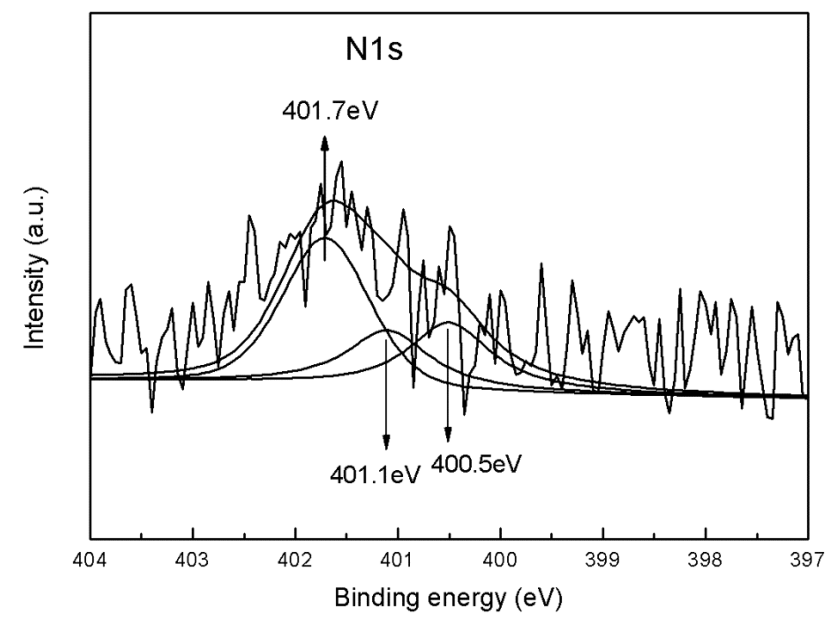

Fig. 3. XPS spectrum of the $\mathrm{N}$ 1s of $\mathrm{Na}(\mathrm{ANIH})_{4} \mathrm{ANI}\left[\mathrm{PW}{ }_{11} \mathrm{Ni}(\mathrm{ANI}) \mathrm{O}_{39}\right]$. $12 \mathrm{H}_{2} \mathrm{O}$

two peaks at 856.1 and $873.7 \mathrm{eV}$ are attributed to $\mathrm{Ni}^{2+}\left(2 \mathrm{p}_{3 / 2}\right)$ and $\mathrm{Ni}^{2+}\left(2 \mathrm{p}_{1 / 2}\right)^{18}$, respectively. For the as-prepared hybrid material, two peaks at 855.5 and $873.5 \mathrm{eV}$ are attributed to $\mathrm{Ni}^{2+}\left(2 \mathrm{p}_{3 / 2}\right)$ and $\mathrm{Ni}^{2+}\left(2 \mathrm{p}_{1 / 2}\right)$, respectively. The position of $\mathrm{N}$ core-level peak of the as-prepared hybrid material is observed at $401.6 \mathrm{eV}$, which is consistent with N1s. The N1s core level can be deconvoluted into three peaks with the binding energy centered at ca. 401.7, 401.1 and $400.5 \mathrm{eV}$, respectively, indicating that there are three different states of nitrogen atom on the surface of the hybrid material. The highest energy contribution of the peak at $401.7 \mathrm{eV}$ is attributed to $\mathrm{ANIH}^{+}$in the hybrid material ${ }^{19}$, which accords with the results of IR spectra. Compared with the peak at $399.8 \mathrm{eV}$ of pure aniline nitrogen $^{20}$, the increased binding energy at $c a .400 .5 \mathrm{eV}$ can be assigned to $\mathrm{Ni}-\mathrm{N}$ covalent bond. It is well-known that the binding energy of $\mathrm{N} 1 \mathrm{~s}$ increases to higher value when nitrogen is bound to metals ${ }^{21}$. The other weak N1s peak at $401.1 \mathrm{eV}$ means the presence of the $\mathrm{N}$ atom from the noncoordinated ANI molecule ${ }^{22}$. The binding energy of nickel on the surface of the hybrid material is decreased by $0.2-0.6 \mathrm{eV}$ versus nickel in $\mathrm{K}_{5}\left[\mathrm{PW}_{11} \mathrm{Ni}\left(\mathrm{H}_{2} \mathrm{O}\right) \mathrm{O}_{39}\right]$ (Table-1), while the binding energy of N1s from Ni-N covalent bond on the surface of the hybrid material is increased by $0.7 \mathrm{eV}$ versus $\mathrm{N} 1 \mathrm{~s}$ on the surface of aniline. The shift of the binding energies of $\mathrm{Ni}$ and $\mathrm{N}$ core level is possibly due to the change in the coordination environment of $\mathrm{Ni}$ and $\mathrm{N}$ atom on the surface of the hybrid material. The above results reflect that the density of electrons on nitrogen decrease and that on nickel increases, indicating that the electrons transfer from the nitrogen atom of aniline to the transitionmetal center $(\mathrm{Ni})$ in the Keggin-type anion $\left[\mathrm{PW}_{11} \mathrm{Ni}\left(\mathrm{H}_{2} \mathrm{O}\right) \mathrm{O}_{39}\right]^{5-}$, resulting in the formation of $\mathrm{Ni}-\mathrm{N}$ covalent bond. The XPS result proves that Ni-N covalent bond is formed and $\left[\mathrm{PW}_{11} \mathrm{Ni}(\mathrm{ANI}) \mathrm{O}_{39}\right]^{5-}$ anion is surrounded by five aniline containing species: four of them are protonated $\mathrm{ANIH}^{+}$and one is noncoordinated ANI molecule.

TG-DTA analysis: Elemental analysis and TG-DTA results confirm the formula of the hybrid material. The TG-DTA profiles of the as-prepared hybrid material are shown in Fig. 4. A twostep weight loss is shown: the weight loss of $6.04 \%$ during the first step from $30-177^{\circ} \mathrm{C}$ corresponds to the loss of all water molecules (calcd. $6.11 \%$ ). The second weight loss is $16.3 \%$ between 178 and $700{ }^{\circ} \mathrm{C}$, which accords with the loss of four protonated $\mathrm{ANIH}^{+}$ions, one noncoordinated ANI molecule and one coordinated ANI molecule (calcd. 15.89\%).

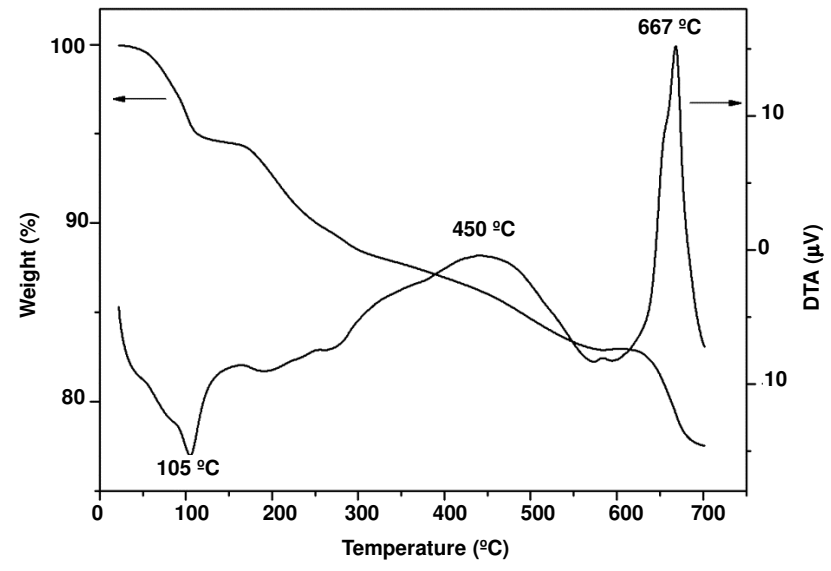

Fig. 4. TG-DTA curves of $\mathrm{Na}(\mathrm{ANIH})_{4} \mathrm{ANI}\left[\mathrm{PW}_{11} \mathrm{Ni}(\mathrm{ANI}) \mathrm{O}_{39}\right] \cdot 12 \mathrm{H}_{2} \mathrm{O}$

\begin{tabular}{|c|c|c|c|c|}
\hline \multirow{3}{*}{ XPS peaks } & \multicolumn{4}{|c|}{ 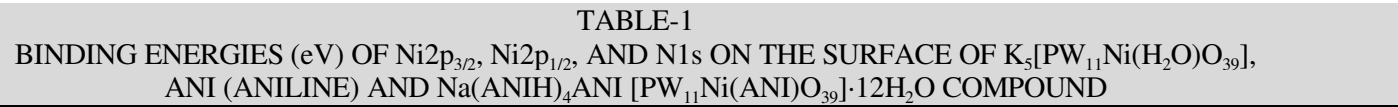 } \\
\hline & \multicolumn{3}{|c|}{ Binding energy $(\mathrm{eV})$} & \multirow{2}{*}{$\Delta \mathrm{E}_{\mathrm{b}}(\mathrm{eV})$} \\
\hline & $\mathrm{K}_{5}\left[\mathrm{PW}_{11} \mathrm{Ni}\left(\mathrm{H}_{2} \mathrm{O}\right) \mathrm{O}_{39}\right]$ & $\mathrm{Na}(\mathrm{ANIH})_{4} \mathrm{ANI}\left[\mathrm{PW}_{11} \mathrm{Ni}(\mathrm{ANI}) \mathrm{O}_{39}\right] \cdot 12 \mathrm{H}_{2} \mathrm{O}$ & ANI & \\
\hline $\mathrm{Ni}_{2 \mathrm{p} 3 / 2}^{2+}$ & 856.1 & 855.5 & - & -0.6 \\
\hline $\mathrm{Ni}^{2+}{ }_{2 \mathrm{p} 1 / 2}$ & 873.7 & 873.5 & - & -0.2 \\
\hline $\mathrm{N}_{1 \mathrm{~s}}$ & - & $401.7^{\mathrm{a}}$ & - & - \\
\hline- & - & $401.1^{\mathrm{b}}$ & - & - \\
\hline- & - & $400.5^{\mathrm{c}}$ & 399.8 & 0.7 \\
\hline
\end{tabular}

${ }^{a} \mathrm{ANIH}^{+} .{ }^{\mathrm{b}}$ Noncoordinated ANI. ${ }^{\mathrm{N}} \mathrm{Ni}-\mathrm{ANI}$. 
In the DTA curve of the hybrid material, there is one endothermal peak and two exothermic peaks corresponding to the weight losses of the TG curve. The strong endothermal peak is observed at $105{ }^{\circ} \mathrm{C}$, which should be related to the release of the water molecules. Meanwhile, the two exothermic peaks appearing at 450 and $667^{\circ} \mathrm{C}$ are attributed to the loss of $\mathrm{ANIH}^{+}$cation and ANI molecules. From the results above, the formula of the hybrid material can be deduced to be $\mathrm{Na}(\mathrm{ANIH})_{4} \mathrm{ANI}\left[\mathrm{PW}{ }_{11} \mathrm{Ni}(\mathrm{ANI}) \mathrm{O}_{39}\right] \cdot 12 \mathrm{H}_{2} \mathrm{O}$.

Photocatalytic activity: Rhodamine B was selected as the target to investigate the photocatalytic activity of the asprepared hybrid material $\mathrm{Na}(\mathrm{ANIH})_{4} \mathrm{ANI}\left[\mathrm{PW}_{11} \mathrm{Ni}(\mathrm{ANI}) \mathrm{O}_{39}\right]$. $12 \mathrm{H}_{2} \mathrm{O}$. As shown in Fig. 5 disappearance of rhodamine B (10 $\mathrm{mg} \mathrm{L}^{-1}, 150 \mathrm{~mL}$ ) was monitored by a UV-visible spectrometry at wavelength of $554 \mathrm{~nm}$. In the absence of the catalyst, direct photolysis of rhodamine B under UV irradiation for 180 min does not cause obvious degradation. When suspension of aqueous rhodamine $\mathrm{B}$ solution $\left(10 \mathrm{mg} \mathrm{L}^{-1}\right)$ and the catalyst powder (including $40 \mathrm{mg}$ of hybrid material $\mathrm{Na}(\mathrm{ANIH})_{4} \mathrm{ANI}\left[\mathrm{PW}_{11} \mathrm{Ni}(\mathrm{ANI}) \mathrm{O}_{39}\right]$. $12 \mathrm{H}_{2} \mathrm{O}$ or $\left.\mathrm{K}_{5}\left[\mathrm{PW}_{11} \mathrm{Ni}\left(\mathrm{H}_{2} \mathrm{O}\right) \mathrm{O}_{39}\right]\right)$ were mixed and stirred in the dark for $180 \mathrm{~min}$, a good dispersion occurred and an adsorption-desorption equilibrium established. In the homogeneous system of an aqueous rhodamine $\mathrm{B}$ solution and $\mathrm{K}_{5}\left[\mathrm{PW}_{11} \mathrm{Ni}\left(\mathrm{H}_{2} \mathrm{O}\right) \mathrm{O}_{39}\right]$, the photocatalytic activity of $\mathrm{K}_{5}\left[\mathrm{PW}_{11} \mathrm{Ni}\left(\mathrm{H}_{2} \mathrm{O}\right) \mathrm{O}_{39}\right]$ for photodegradation of rhodamine $\mathrm{B}$ is low and the conversion of rhodamine $\mathrm{B}$ is $10.66 \%$. However, the conversion of rhodamine $\mathrm{B}$ is $59.73 \%$ over the as-prepared hybrid material. The photocatalytic activity of $\mathrm{Na}(\mathrm{ANIH})_{4} \mathrm{ANI}$ $\left[\mathrm{PW}_{11} \mathrm{Ni}(\mathrm{ANI}) \mathrm{O}_{39}\right] \cdot 12 \mathrm{H}_{2} \mathrm{O}$ is much higher than that of $\mathrm{K}_{5}\left[\mathrm{PW}_{11} \mathrm{Ni}\left(\mathrm{H}_{2} \mathrm{O}\right) \mathrm{O}_{39}\right]$. This result indicates that the as-prepared hybrid material exhibits favorable photocatalytic activity for degradation of rhodamine $\mathrm{B}$ and can be used for treating the dye-containing wastewater.

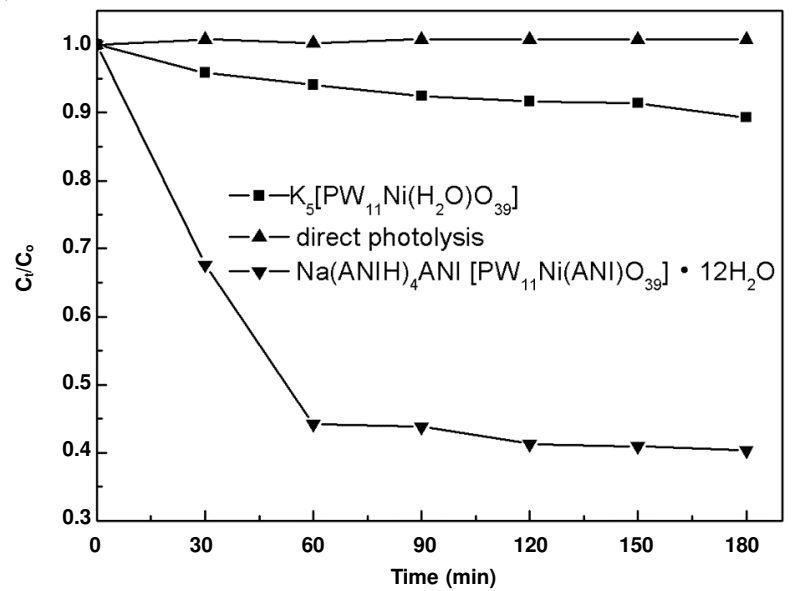

Fig. 5. Photocatalytic degradation of rhodamine $B\left(10 \mathrm{mg} \mathrm{L}^{-1}\right)$ in aqueous dispersions of different catalytic materials under UV irradiation

\section{Conclusion}

A novel inorganic-organic hybrid material $\mathrm{Na}(\mathrm{ANIH})_{4} \mathrm{ANI}$ $\left[\mathrm{PW}_{11} \mathrm{Ni}(\mathrm{ANI}) \mathrm{O}_{39}\right] \cdot 12 \mathrm{H}_{2} \mathrm{O}$ was successfully synthesized. The hybrid material was prepared based on transition-metal monosubstituted Keggin-type anion $\left[\mathrm{PW}_{11} \mathrm{Ni}\left(\mathrm{H}_{2} \mathrm{O}\right) \mathrm{O}_{39}\right]^{5-}$ and organic ligand aniline by covalent bonding of $\mathrm{Ni}-\mathrm{N}$. Characterization of the as-prepared hybrid material illuminated that the Ni-N covalent bond was formed between transition-metal in the Keggin-type anion $\left[\mathrm{PW}_{11} \mathrm{Ni}\left(\mathrm{H}_{2} \mathrm{O}\right) \mathrm{O}_{39}\right]^{5-}$ and the nitrogen atom of ANI molecule, indicating that polyoxometalate anions reacted chemically with organic ligand and electrons transferred from the nitrogen atom to the transition metal center. Also the anion $\left[\mathrm{PW}_{11} \mathrm{Ni}(\mathrm{ANI}) \mathrm{O}_{39}\right]^{5-}$ was surrounded by five aniline containing species: four of them were protonated $\mathrm{ANIH}^{+}$as counter-ions and one was noncoordinated ANI molecule. Photocatalytic degradation of dye rhodamine $\mathrm{B}$ indicated that the as-prepared hybrid material $\mathrm{Na}(\mathrm{ANIH})_{4} \mathrm{ANI}$ $\left[\mathrm{PW}_{11} \mathrm{Ni}(\mathrm{ANI}) \mathrm{O}_{39}\right] \cdot 12 \mathrm{H}_{2} \mathrm{O}$ showed higher photocatalytic activity than $\mathrm{K}_{5}\left[\mathrm{PW}_{11} \mathrm{Ni}\left(\mathrm{H}_{2} \mathrm{O}\right) \mathrm{O}_{39}\right]$. Therefore, the hybrid material has great potential for application in practical photodegradation. The interaction of the organic ligand with the transition-metal center of the polyoxometalates results in the formation of covalent bond. Based on this mechanism a variety of hybrid materials can be designed, prepared and applied in many fields.

\section{ACKNOWLEDGEMENTS}

The authors appreciated the financial support from the Jilin Province Science \& Technology Department Foundation of China (20101545).

\section{REFERENCES}

1. B. Hasenknopf, K. Micoine, E. Lacôte, S. Thorimbert, M. Malacria and R. Thouvenot, Eur. J. Inorg. Chem., 5001 (2008).

2. R. Tayebee, Asian. J. Chem., 21, 5791 (2009).

3. C.C. Wang, Asian. J. Chem., 21, 4755, 4919 (2009).

4. I. Bar-Nahum, J. Ettedgui, L. Konstantinovski, V. Kogan and R. Neumann, Inorg. Chem., 46, 5798 (2007).

5. W. Qi and L.X. Wu, Polym. Int., 58, 1217 (2009).

6. Y. Wei, B. Xu, C.L. Barnes and Z. Peng, J. Am. Chem. Soc., 123, 4083 (2001).

7. I. Bar-Nahum, K.V. Narasimhulu, L. Weiner and R. Neumann, Inorg. Chem., 44, 4900 (2005).

8. J.B. Strong, R. Ostrander, A.L. Rheingold and E.A. Maatta, J. Am. Chem. Soc., 116, 3601 (1994).

9. W. Clegg, R.J. Errington, K.A. Fraser, S.A. Holmes and A. Schäfer, J. Chem. Soc. Chem. Commun., 4, 455 (1995).

10. A. Proust, R. Thouvenot, M. Chaussade, F. Robert and P. Gouzerh, Inorg. Chim. Acta, 224, 81 (1994).

11. D.E. Katsoulis, Chem. Rev., 98, 359 (1998).

12. T.J.R. Weakley and S.A. Malik, J. Inorg. Nucl. Chem., 29, 2935 (1967).

13. J.L. Hu, K.X. Li, W. Li, F.Y. Ma and Y.H. Guo, Appl. Catal. A, 364, 211 (2009)

14. J.A. Gamelas, F.A.S. Couto, M.C.N. Trovao, A.M.V. Cavaleiro, J.A.S. Cavaleiro and J.D. Pedrosa de Jesus, Thermochim. Acta, 326, 165 (1999).

15. J.C. Evans, Spectrochim. Acta, 16, 428 (1960).

16. K. Fukaya, A. Srifa, E. Isikawa and H. Naruke, J. Mol. Struct., 979, 221 (2010).

17. D.F. Li, Y.H. Guo, C.W. Hu, L. Mao and E.B. Wang, Appl. Catal. A, 235, 11 (2002).

18. S.Z. Li, J.W. Zhao, P.T. Ma, J. Du, J.Y. Niu and J.P. Wang, Inorg. Chem., 48, 9819 (2009).

19. S. Yau, Y.H. Lee, C.Z. Chang, L.J. Fan, Y.W. Yang and W.P. Dow, J. Phys. Chem. C, 113,13758 (2009).

20. C.A. Amarnath, C.E. Hong, N.H. Kim, B.C. Ku and J.H. Lee, Mater. Lett., 65, 1371 (2011).

21. S.Q. Li, C.X. Zhu, L. Tang and J.Q. Kan, Mater. Chem. Phys., 124, 168 (2010).

22. L. Xu, M.Q. Li and E.B. Wang, Mater. Lett., 54, 303 (2002). 